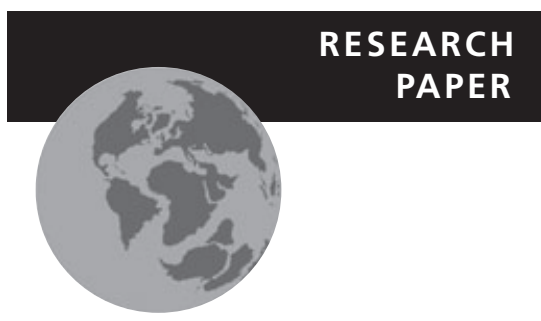

\title{
Ambient, productive and wind energy, and ocean extent predict global species richness of procellariiform seabirds
}

\author{
Richard G. Davies ${ }^{1 \star}$, Ulrike M. Irlich², Steven L. Chown ${ }^{2}$ and \\ Kevin J. Gaston ${ }^{3}$
}

${ }^{1}$ Centre for Ecology, Evolution and Conservation, School of Biological Sciences, University of East Anglia, Norwich NR4 7TJ, UK, ${ }^{2}$ Centre for Invasion Biology, Department of Botany and Zoology, University of Stellenbosch, Private Bag XI, Matieland, 7602, South Africa, ${ }^{3}$ Biodiversity and Macroecology Group, Department of Animal and Plant Sciences, University of Sheffield, Sheffield S10 $2 T N, U K$

${ }^{*}$ Correspondence: Richard G. Davies, Centre for Ecology, Evolution and Conservation, School of Biological Sciences, University of East Anglia, Norwich NR4 7TJ, UK.

E-mail: richard.g.davies@uea.ac.uk

\begin{abstract}
Aims Tests of the energy hypothesis for the large-scale distribution of species richness have largely been concerned with the influence of two alternative forms of environmental energy, temperature and energy from primary productivity, both of which (at least in terrestrial systems) peak within the tropics. Taxa showing extratropical diversity peaks present a potential challenge to the generality of speciesenergy theory. One such group are pelagic seabirds of the order Procellariiformes that show not only an extra-tropical diversity peak but one confined to the Southern Ocean, hence a highly asymmetric one. They are distinct in being exceptionally adapted to take advantage of wind energy, which they may rely on for long-distance ocean foraging for the patchy resources needed to meet their energetic needs. Wind represents a readily available source of kinetic energy, shows a strong latitudinal gradient, and has been largely omitted from species-energy theory. Moreover, maximal benefits of wind are likely to be afforded in areas of greatest available contiguous ocean extent. We compare the relative importance of wind speed, ocean productivity (chlorophyll concentration), air temperature and available ocean extent (distance) in explaining large-scale global distribution of procellariiform species richness across the world's oceans.
\end{abstract}

Location Global, oceanic.

Methods Hierarchical partitioning, model selection, ordinary least squares (OLS) and spatial generalized least squares (GLS) regression.

Results Hierarchical partitioning of non-spatial regression models indicates that ocean distance is the most important predictor of procellariiform species richness followed by wind speed and then temperature. In contrast, that of spatial regression models indicates the roughly equal importance of ocean distance and temperature, followed by wind speed. Although contributing additional model fit, ocean productivity is consistently the weakest predictor. Best-fit models include all four predictors and explain $67 \%$ of observed variation. The species-productivity relationship is negative overall, while the species-temperature relationship is humpshaped. In contrast, ocean distance and wind speed are positively associated with species richness.

Conclusions Large-scale procellariiform species richness distribution may represent a trade-off in the use of different energy forms, being highest in Southern Ocean areas where productive energy and temperature are relatively low, but where available ocean foraging extent and wind energy required to utilize it are near-maximal.

\section{Keywords}

Available energy, foraging energetics, latitudinal diversity gradient, species richness, species-energy theory, wind speed. 


\section{INTRODUCTION}

The great majority of taxa exhibit a latitudinal gradient in diversity with species richness declining from the tropics to the poles. Of the numerous theories proposed to explain the gradient, species-energy theory has received the most widespread empirical support (Evans et al., 2005). To date, tests of species-energy theory have been largely framed with reference to two alternative energy hypotheses, the ambient or solar energy hypothesis and the productive energy hypothesis. The former derives from the observation that temperature limits the distributional ranges of species via physiological constraints and, in homeotherms, limits the energy available for reproduction, hence influencing population numbers and local extinction risk (Turner et al., 1987, 1988; Currie, 1991). The hypothesis also encompasses the influence of solar energy upon speciation rates, via the causal link between ultraviolet (UV) radiation and mutation rates (Rohde, 1992). Productive energy, starting with biomass resulting from primary productivity, and hence dependent on the availability of water, heat and light, is predicted to limit species richness via the energy flowing through food webs (Wright et al., 1993).

Nevertheless, a number of taxa show extra-tropical peaks in species richness, and while these tend to be taxonomically restricted, they nevertheless present a potential challenge to the general validity of theories for the large-scale distribution of biodiversity. Plausible explanations for such extra-tropical peaks include the exceptional importance of other biotic or abiotic environmental processes, or the existence of energy fluxes that peak outside the tropics. One such taxon is the group of pelagic seabirds of the order Procellariiformes (e.g. albatrosses, petrels, storm petrels and shearwaters). The challenge in understanding the large-scale species richness distribution of this taxon lies in its remarkable asymmetry, with a band of maximum species numbers around the Southern Ocean but no equivalent peak in the Northern Hemisphere.

A previous test of global species-energy relationships in procellariiform seabirds focused on the productive energy hypothesis, and found a hump-shaped relationship between remotely sensed chlorophyll concentration and species richness (Chown \& Gaston, 1999). The negative phase of this relationship may be explained by an increase in temporal variability in energy availability at higher productive energy levels. A number of more local-scale seabird studies indicate temperature to be an important variable limiting seabird distributions (Abrams, 1985; Hunt et al., 1992; Ainley et al., 1994; Inchausti et al., 2003), and this influence could be expected to operate at macroecological scales (Chown \& Gaston, 1999) as demonstrated for other taxa (Willig et al., 2003; Evans et al., 2005). More recently, wind energy has been implicated in the distribution of seabird species richness around coastlines (Hashmi \& Causey, 2008). Nevertheless, the variance in species richness explained in these studies has been fairly modest (between $29 \%$ and $43 \%$ ), in comparison with studies of large-scale terrestrial species richness which typically account for $60 \%$ or more of variation. Moreover, their geographical extents and focus of enquiry have been relatively circumscribed, and hence the latitudinal asymmetry in species richness has remained unaccounted for.

Global patterns of variation in wind energy availability remain largely neglected with respect to their macroecological significance. Variation in average wind speed shows a marked latitudinal gradient over both land and sea, with the highest energy at high latitudes rather than the equator (for ocean data see Fig. 1). The potential energy savings afforded to any group of organisms that can harness wind energy are considerable and may offset corresponding deficits in the availability of other forms of energy. Specifically, wind energy may enhance the viability of exploiting otherwise marginal or patchily distributed sources of productive energy by lowering the costs of transport associated with interpatch movement.

One of the major constraints on successful breeding of pelagic seabirds is the scarcity and patchy distribution of marine resources that demands energy-efficient foraging over wide areas of ocean (Lack, 1968; Ashmole, 1971). Evidence from energetic and physiological studies points to the importance of wind speed in the foraging and life history of procellariiform seabirds. This comes mainly from studies of albatrosses, but is not restricted to these species (Warham, 1996). High wind energy is essential for dynamical gust soaring by albatrosses (Wilson, 1975; Pennycuick, 1982, 2002) with greater body size predicted to require greater wind speeds in order to achieve optimal gliding performance (Pennycuick, 1989). In Diomedea exulans (the wandering albatross), studies of metabolic rate in relation to foraging behaviour (Shaffer et al., 2001) and of heart-rate (Weimerskirch et al., 2000) indicate that flapping flight is very expensive relative to gliding. Hence, this species remains on the water when wind speeds are too low for soaring (Jouventin \& Weimerskirch, 1990) and its efficient use of gliding flight enables

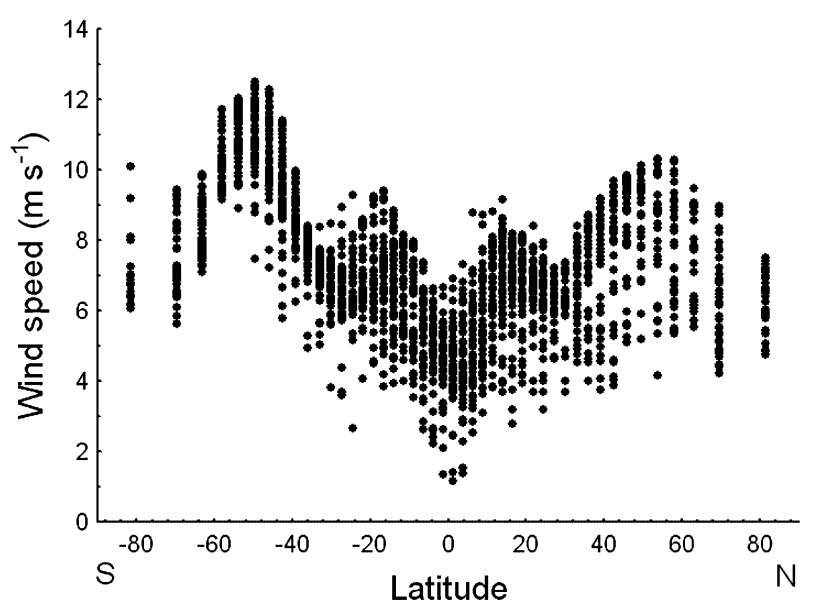

Figure 1 Plot of mean annual wind speed $\left(\mathrm{m} \mathrm{s}^{-1}\right)$ against latitude across ocean, taken from global data sampled to an equal-area (Peter's) projection grid at a resolution measuring $392.4 \times$ $392.4 \mathrm{~km}$ at the latitude of true distance (i.e. $45^{\circ} \mathrm{N} / \mathrm{S}$ ). The Southern Hemisphere is represented by negative latitudes. 
it to maintain the lowest mass-specific field metabolic rates (FMR) recorded for any flighted seabird (Adams et al., 1986). Indeed, studies show that both basal and field metabolic rates are lower for species that glide or flap-glide relative to those that only flap (e.g. Ellis, 1984; Birt-Friesen et al., 1989). Hence, procellariiform seabirds in general are able to maintain relatively low mass-specific FMRs (Nagy et al., 1999). Moreover, the negative relationship between wind speed and metabolic costs of foraging observed in a study of Fulmarus glacialis (the northern fulmar) gave rise to the hypothesis that wind energy may limit the breeding range of this species, and possibly that of other gliding/flap-gliding procellariiforms (Furness \& Bryant, 1997).

Global hemispheric asymmetries in the extent and connectivity of available ocean areas may additionally regulate the influence of wind energy on species foraging distributions. We would expect greatest species richness to occur where high levels of available wind energy enabling efficient acquisition of marine resources using soaring flight coincide with large areas of contiguous ocean. In other words, high average wind speeds will maximize the total resource base available to seabirds in areas where ocean extent matches the maximal wind-assisted foraging range of individuals. Studies of a number of breeding species have shown the use of a twofold foraging strategy during breeding that may be a general rule in pelagic procellariiform seabirds (Weimerskirch, 1998), where short-distance foraging trips allow maximal rates of food delivery to the chick at the expense of adult body weight and condition, while longdistance trips enable adult birds to regain weight and condition (Chaurand \& Weimerskirch, 1994; Weimerskirch et al., 1997; Weimerskirch, 1998). Satellite tracking of wandering albatrosses suggests that longer trips are more predictable and profitable, through the flight and foraging efficiencies afforded by the use of favourable wind conditions, while short trips take little advantage of wind and involve numerous expensive take-offs and landings (Weimerskirch et al., 1993; Weimerskirch, 1998). Hence, by using wind to facilitate long-distance foraging, pelagic seabirds may be relatively unlimited (except by major land barriers) in their ability to take advantage of the potentially vast areas of ocean they can exploit for resources. This ability is perhaps epitomised in the regular circumnavigations of the Southern Ocean by certain albatross species (Croxall et al., 2005). There is clearly a large disparity in ocean extent and contiguity between the Northern and Southern hemispheres, which may contribute to the latitudinal asymmetry in procellariiform species richness distribution.

This paper compares the relative importance of large-scale availability of ocean extent (by distance) and three forms of energy availability (temperature, ocean productivity and wind speed) in predicting the global distribution of procellariiform seabird species richness as determined from non-migratory foraging ranges. The importance of mean ocean distance in explaining the asymmetry in the procellariiform latitudinal diversity gradient is discussed, and the likely role of global wind speed gradients is highlighted.

\section{METHODS}

\section{Species data}

Species distributional range map data for 110 procellariiform seabirds were taken from Harrison (1989) supplemented for newly erected taxa by information from Brooke (2004). Harrison's data were chosen over those of Brooke (2004) since the latter work does not distinguish between migratory and nonmigratory ranges in its illustration of individual species distributions. We use non-migratory ranges as the basis of our data analysis. Within these areas, we do not distinguish between the breeding islands/areas and non-breeding ranges of Harrison's distribution maps since the former are a very minor subset in space of the latter and delineate highly circumscribed areas effectively only encircling the islands upon which individual species breed. Such breeding islands/areas delineated in Harrison (1989) therefore do not represent the true ranges over which albatross and petrel species forage during the breeding season. Not only do many individuals of both petrel and albatross species remain within the non-breeding range during the breeding season, but mated pairs take it in turns to incubate, allowing time off for a breeding bird to forage over many thousands of kilometres of ocean distance to maintain body condition (e.g. Chaurand \& Weimerskirch, 1994; Weimerskirch et al., 1997; Weimerskirch, 1998). The concept of breeding versus nonbreeding ranges in this pelagic group is therefore problematic, compared with its more ready application to terrestrial groups. Hence, we consider the combination of both areas defined in Harrison's maps as species foraging ranges. These were plotted on a cylindrical equal-area (Peter's) projection map of the world, overlaid with an equal-area grid corresponding to a resolution of $392.435 \times 392.435 \mathrm{~km}$ at the latitude of true distance (i.e. $45^{\circ} \mathrm{N}$ and S) using WORLDMAP version 4.2 (Williams, 1999). The resolution corresponds to $5^{\circ}$ of longitude giving a cell area of $c .154,005 \mathrm{~km}^{2}$. Whilst coarse, this represents a reasonable compromise between the greater precision provided by finer mapping resolution and the quality of the underlying distributional data over vast areas of ocean. Since some grid cells are only partially occupied by a given species, we followed the method used by Blackburn et al. (1998) where only instances of $25 \%$ or more of grid cell occupancy by a species' range counted as presence.

\section{Environmental data}

Global ocean data for each of the three energy variables were reprojected and resampled to the same equal-area grid as the species richness data. (1) Remotely sensed mean annual chlorophyll concentration (CHLORO) data, used as a surrogate for ocean productivity (hence productive energy), were obtained at $1^{\circ}$ resolution from the Coastal Zone Color Scanner (CZCS) on the Nimbus-7 satellite for the period 1978-86 inclusive (available at: http://oceancolor.gsfc.nasa.gov/ftp.html). Estimates of chlorophyll concentration $\left(\mathrm{mg} \mathrm{m}^{-3}\right)$ are derived from ocean colour variation caused by reflectance of the photosyn- 
thetic pigment concentration of the water (Hovis et al., 1980; Platt \& Sathyendranath, 1988). (2) Mean air temperature (TEMP) data were obtained at $2.5^{\circ}$ resolution from the National Center for Atmospheric Research/National Centers for Environment Prediction (NCAR/NCEP) Reanalysis Data for the period 1991-2000 inclusive (available at: http:// www.cru.uea.ac.uk/cru/data/ncep/); and (3) Mean annual ocean wind speed (WIND) data were obtained at $2.5^{\circ}$ resolution, calculated as the overall mean of the annual averages also for the period 1991-2000 using the same data source as for temperature.

The predictor variable ocean distance (OCEAN-DIST), as an index of the extent of ocean expanse contiguous with any given ocean grid cell, and hence potentially available to foraging seabirds, was calculated as the average of two separate components: the distance $(\mathrm{km})$ of continuous ocean along an east-west axis intersecting the centre of each grid cell, hence longitudinal ocean distance; and the continuous ocean distance intersecting along a north-south axis, hence latitudinal ocean distance. Continuous distance was defined as the length along each of the above axes that was uninterrupted by any major land mass while intersecting with the grid cell in question (defined as land masses larger than $100,000 \mathrm{~km}^{2}$ ).

Data for two additional covariates, total island area and total ocean area, were also used. Islands are essential nesting sites for most procellariiform seabirds, and hence total island area in each grid cell was an important factor to control for when comparing energy variables as predictors of seabird species richness. Island area was obtained by creating a grid in ARCVIEw GIS software (ESRI version 9.2) that matched the WORLDMAP grid in both extent and resolution, and then overlaying this grid with the Digital Chart of the World (ESRI, 1993) and computing total island area $\left(\mathrm{km}^{2}\right)$ per grid cell, where an island is defined as any land area less than $10,000 \mathrm{~km}^{2}$. Although an equal-area grid was used, variation in the amount of ocean area within grid cells may bias species richness values through species-area effects, and hence this covariate was derived in the same way as for total island area.

\section{Analyses}

The response variable, species richness of procellariiform seabirds, was normalized with a $\log _{10}$-transformation. Chlorophyll concentration was double- $\log _{10}$-transformed prior to analysis. Wind speed, temperature and measures of ocean distance remained untransformed in analyses. Use of ordinary least squares (OLS) regression methods that assume independent errors may render correlation coefficients or regression slopes misleading (Clifford et al., 1989; Cressie, 1991). Hence, in addition to carrying out standard non-spatial OLS regression, we used generalized least squares (GLS) regression in which exponential spatial covariance structures are fitted, since these were the best-fit choice among spatial covariance options, as indicated by lowest value of Akaike's information criterion (AIC). Longitudinal and latitudinal cell centroid values were used as spatial variables and all models were implemented in sas version
9.2 using the PROC MIXED procedure (Littell et al., 1996). Chown et al. (1998a) showed that large-scale distribution of procellariiform species richness varies among the three major ocean basins, Atlantic, Indian and Pacific. Spatial models therefore took account of the differences among these ocean basins in the maximum geographical distance or range parameter $(\rho)$, measured in degrees, over which spatial autocorrelation in equivalent OLS residuals was observed to occur. This involved estimating $\rho$ from the semi-variogram of residuals of standard OLS models that included the relevant combination of predictors separately for each ocean basin (implemented in sAs version 9.2 using the PROC VARIOGRAM procedure). Since spatial covariance parameter searches in PROC MIXED proved unstable, we used semi-variograms in preference, as recommended by Littell et al. (1996). All three estimates of $\rho$ were then entered as spatial covariance parameters in the model, with spatial autocorrelation assumed for observations within the same ocean basin. Values for a 'nugget' parameter were not used in any of the models since exploratory trials showed fitting of a nugget decreased model fit (an increase in AIC) and semivariograms indicated that no-nugget models were appropriate. The significance of spatial autocorrelation in OLS residuals across the estimated range distances was confirmed from the $P$-values associated with values of Moran's $I$ computed for a number of lag distance classes of equal sample size that together spanned the estimated distance $\rho$. The latter was implemented in Spatial Analysis for Macroecology (SAM) software version 1.1 (Rangel et al., 2005, 2006), and showed $P<0.01$ in all cases.

OLS and GLS regression models for procellariiform species richness were carried out for all possible combinations of environmental predictors and model selection procedures implemented using the AIC to compare the fit of competing models, since this approach is rapidly gaining acceptance as the preferred alternative to null hypothesis testing (Burnham \& Anderson, 2002; Westphal et al., 2003; Johnson \& Omland, 2004; DinizFilho et al., 2008). Since a priori expectations of nonlinear fit of all three energy forms as well as OCEAN-DIST are not unreasonable, combinations included those in which quadratic terms for each of the four predictor variables were fitted. The covariates, island area and ocean area, were fitted as linear terms in all models since there were no strong a priori reasons for assuming a quadratic relationship for either of these, and a trial of nonspatial models confirmed this. Following Burnham \& Anderson (2002), Westphal et al. (2003) and Johnson \& Omland (2004), we calculated $\Delta_{i}$, or the difference between each model's AIC value and that of the best-fitting model, the one with the smallest AIC (hence, $\Delta_{i}=\mathrm{AIC}_{i}-\mathrm{AIC}_{\min }$ ). The Akaike weight $(W)$ of each model was then derived as

$$
W_{i}=\frac{\exp \left(1 / 2 \Delta_{i}\right)}{\sum_{j=i}^{R} \exp \left(-1 / 2 \Delta_{j}\right)}
$$

$W$ for each model is the model likelihood value normalized to sum to 1 across all $R$ models being considered, and can be interpreted as the probability that each model provides the best 
fit among all models to explain the observed data. OLS and GLS models were treated as entirely separate groups in these calculations. We then determined candidate sets of models for the OLS and GLS models by only including those with $W \geq 0.1$. We computed the overall adjusted $r^{2}$ for the OLS models; however, we omit comparable estimates of variance explained for GLS models on account of their difficulty in interpretation and questionable robustness.

Assessment of the likely influence of multicollinearity among model predictors using tolerance levels indicated that these were sufficiently high, being above 0.1 in all cases (Table 1; Quinn \& Keough, 2002). Nevertheless, we evaluated the independent and joint contributions of each of our predictors of interest using hierarchical partitioning methods (Chevan \& Sutherland, 1991; MacNally, 2000). For all possible combinations of predictor variables the average independent and joint effects of each predictor were calculated. When performing hierarchical partitioning on the non-spatial OLS models we used the model-adjusted $r^{2}$ as the measure of fit being partitioned, whereas in the case of spatial GLS models we used the residual log likelihood. A further complication was introduced by the fact that one of the energy predictors showed a strong quadratic relationship with species richness (see TEMP results below) and in order to assess its independent and joint effects, the linear and quadratic terms of this predictor therefore had to be treated in combination. One important reason for doing this was to avoid inflating the estimate of average joint effects of TEMP by erroneously including joint effects shared between linear and quadratic terms since these are obviously strongly collinear. Existing software available to automate the hierarchical partitioning procedure is not yet flexible enough to deal with quadratic relationships. We therefore implemented the method manually using standard spreadsheets and formulae.

\section{RESULTS}

Summing procellariiform species presences within equal-area grid cells resulted in a maximal species richness of 42 occurring

Table 1 Correlation coefficients for pairwise relationships among three energy predictors and one ocean distance predictor, and tolerance values $\left(1-r^{2}\right)$ for each predictor (Quinn \& Keough, 2002) where $r^{2}$ refers to the adjusted $r^{2}$ for multiple regressions of the given predictor against all other predictors.

\begin{tabular}{llrll}
\hline Predictor & CHLORO & TEMP & WIND & OCEAN-DIST \\
\hline CHLORO & - & & & \\
TEMP & -0.604 & - & & \\
WIND & -0.059 & -0.452 & - & \\
OCEAN- DIST & -0.493 & 0.139 & 0.412 & - \\
Tolerance $\left(1-r^{2}\right)$ & 0.433 & 0.395 & 0.527 & 0.608 \\
\hline
\end{tabular}

CHLORO, chlorophyll concentration $\left(\mathrm{mg} \mathrm{m} \mathrm{m}^{-3}\right.$, double- $\log _{10^{-}}$ transformed); TEMP, mean annual air temperature $\left({ }^{\circ} \mathrm{C}\right)$; WIND, mean annual wind speed $\left(\mathrm{m} \mathrm{s}^{-1}\right)$; OCEAN-DIST, mean of longitudinal and latitudinal ocean distance. in two grid cells south of Australia (Fig. 2). As shown in a previous study (Chown et al., 1998a), a somewhat discontinuous band of high species richness was evident across the Southern Hemisphere (Fig. 2), producing a very marked latitudinal asymmetry in species richness peaking between $40^{\circ} \mathrm{S}$ and $50^{\circ} \mathrm{S}$ (Fig. 3).

Two OLS models (models 1 and 2, Table 2) gave a combined probability (cumulative $W$ ) of 1.0 that they included the best-fit model, and both of these showed a value of $W \geq 0.1$. They were very similar models, the difference being that model 2 fitted only the linear term for CHLORO whereas model 1 fitted both linear and quadratic terms. Otherwise both models included the linear term for OCEAN-DIST, and both linear and quadratic terms for WIND and TEMP. Additionally, parameter estimates were closely matching between models, with positive linear relationships indicated between species richness and OCEAN-DIST. A hump-shaped relationship for WIND was indicated across the observed range in global wind speeds, with an extended positive phase from low to moderately high wind speeds, turning over to a shorter negative phase at the highest wind speeds. The slopes for TEMP terms indicate a hump-shaped relationship, with species richness increasing from low to intermediate temperatures and then falling steeply with further increase in temperature. A marginally decelerating negative quadratic, and negative linear, relationship for CHLORO was indicated in the case of models 1 and 2, respectively. The variance explained (adjusted $r^{2}$ ) by each model was $66.7 \%$.

Three spatial GLS models could be considered best-fit models based on the criterion of each having $W \geq 0.1$, and these had a combined probability (cumulative $W$ ) of $99.3 \%$ that one of them was the best model (Table 3 ). The three models corresponded closely in that they all included the linear term only for both OCEAN-DIST and WIND, and both linear and quadratic terms for TEMP. Their only differences reflected the three possible combinations for CHLORO, i.e. inclusion of linear and/or quadratic terms. Nevertheless, the slightly accelerating negative slope of CHLORO in model 1 and the negative linear relationships for models 2 and 3 broadly agreed with the consistently negative relationships indicated by the best-fitting OLS models (Table 2). Quadratic relationships with TEMP in spatial GLS models confirmed similar strongly hump-shaped quadratic relationships to those indicated by the OLS models. It is notable also that having accounted for spatial autocorrelation in model residuals, the fitted relationship for WIND became strongly positive linear in GLS models in contrast with the hump-shaped quadratic relationship indicated by best-fitting multipredictor OLS models.

Best-fit GLS models were associated with lower values for $-2 \times$ the logarithm of the restricted likelihood than best-fitting OLS models, indicating that the GLS models were a consistently more accurate description of the variability in procellariiform species richness (Littell et al., 1996). However, semi-variograms of residuals of non-spatial OLS and spatial GLS best-fit multipredictor models indicated that the latter only marginally reduced the level of spatial autocorrelation (Fig. S1 in Supporting Information). Trialling of longer or shorter range distances 


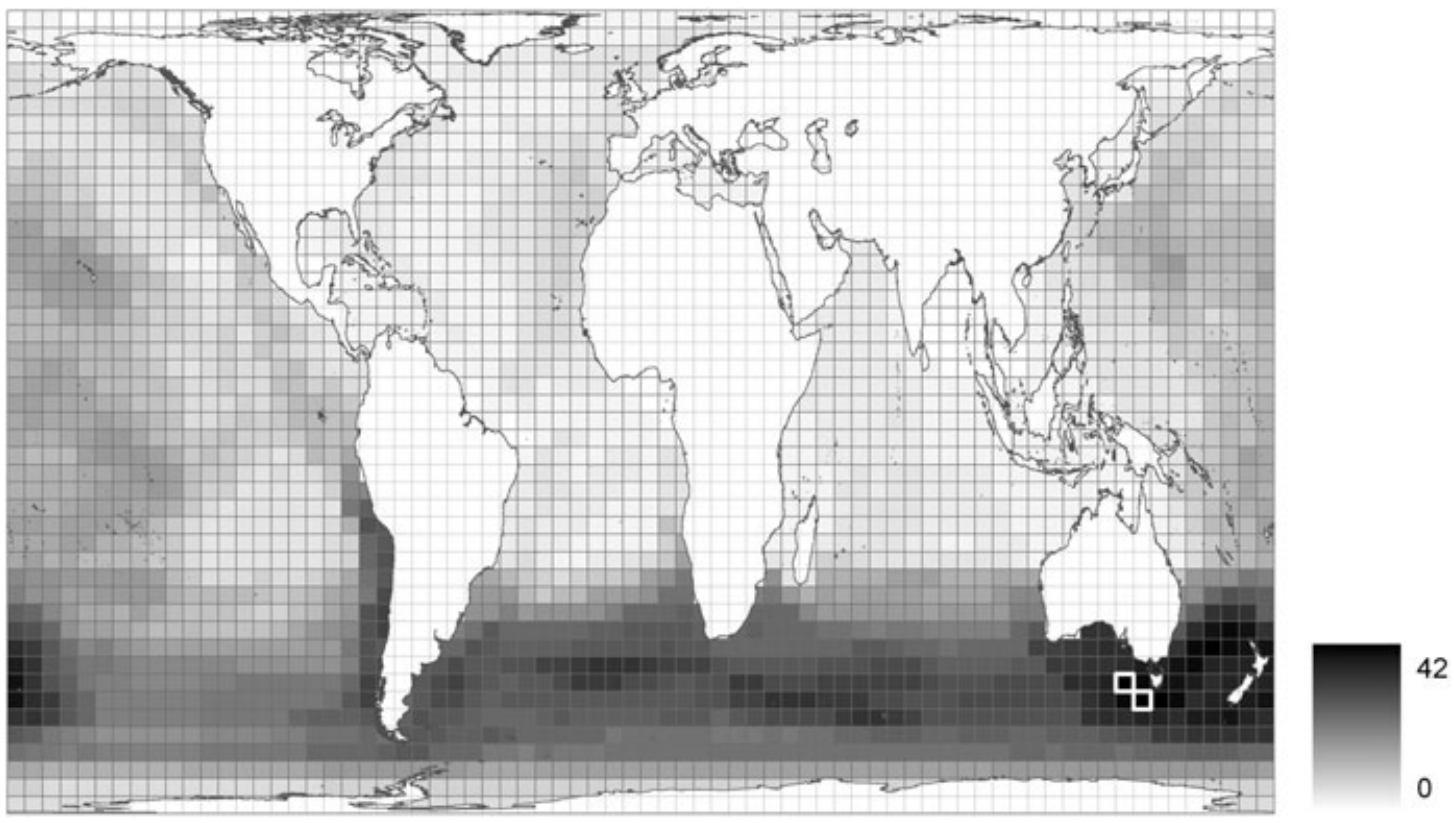

Figure 2 Global distribution of procellariiform species richness mapped to an equal-area (Peter's) projection grid at a resolution measuring $392.4 \times 392.4 \mathrm{~km}$ at the latitude of true distance (i.e. $45^{\circ} \mathrm{N} / \mathrm{S}$ ). Shading indicates species richness from 0 (white) to 42 (black). Two cells showing maximum species richness (42) are bold-outlined in white.

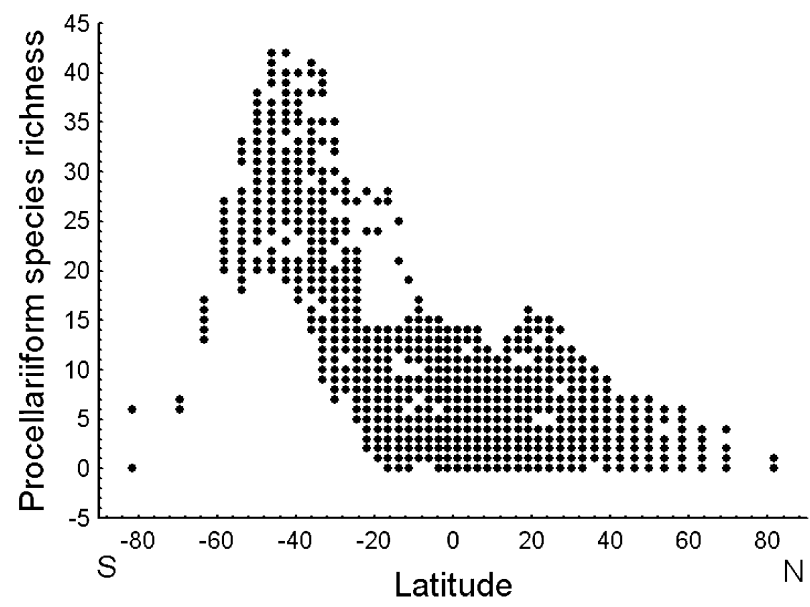

Figure 3 Plot of procellariiform species richness against latitude, taken from global data sampled to an equal-area (Peter's) projection grid at a resolution measuring $392.4 \times 392.4 \mathrm{~km}$ at the latitude of true distance (i.e. $45^{\circ} \mathrm{N} / \mathrm{S}$ ). The Southern Hemisphere is represented by negative latitudes.

over which autocorrelation is modelled, and with alternative spatial covariance structures, did not improve model fit.

In order to test for the relative importance of OCEAN-DIST and the three forms of energy, we summed the Akaike weights of all the models in which terms for the given predictor were included, following Johnson \& Omland (2004). However, for the 255 OLS models, as well as the 255 spatial GLS models, values of $W$ for each predictor summed to 1.0 , indicating that all four were important predictors of species richness and could not be ranked in importance using this method.
Hierarchical partitioning results (Table 4) revealed that OCEAN-DIST had a substantially greater independent explanatory power than any of the energy predictors in non-spatial OLS models. WIND was second in importance in terms of independent contribution, closely followed by TEMP, with CHLORO showing the smallest such contribution. Similarly, OCEANDIST followed by WIND showed strongest joint contributions, followed by TEMP and CHLORO. In contrast, hierarchical partitioning of spatial GLS models indicated that TEMP made the greatest independent contribution to improvement in model log-likelihood, with OCEAN-DIST almost equal in importance. WIND nevertheless showed a relatively substantial independent contribution, with CHLORO again showing the weakest contribution. OCEAN-DIST showed a substantially greater joint contribution to GLS model log-likelihood than all three energy predictors.

Single-predictor linear and quadratic non-spatial OLS models (Table 5) indicated that the linear term for OCEANDIST showed the best fit (lowest AIC) to the species richness data. Second in importance was the linear relationship for WIND, closely followed by the quadratic relationship for TEMP, and lastly the quadratic relationship for CHLORO. For the last of these, the quadratic term only marginally lowered AIC (improving fit), indicating that any nonlinearity is rather subtle and that this is essentially a negative relationship. In contrast, addition of the quadratic term for TEMP greatly improved model fit, reflecting the strongly hump-shaped relationship. The above results contrast with the single-predictor spatial GLS models (Table 6), in that the quadratic relationship for TEMP showed the best fit, with the linear term for OCEAN-DIST showing an almost equally good fit. This was followed by the 
R. G. Davies et al.

Table 2 Best-fit non-spatial ordinary least squares model for procellariiform species richness.

\begin{tabular}{|c|c|c|c|c|c|c|}
\hline \multirow[b]{2}{*}{ Predictor } & \multicolumn{3}{|l|}{ Model 1} & \multicolumn{3}{|l|}{ Model 2} \\
\hline & Slope & SE & $F_{1,2454}$ & Slope & SE & $F_{1,2455}$ \\
\hline OCEAN-DIST & 0.000048 & 0.000001 & 1387.00 & 0.000048 & 0.000001 & 1411.11 \\
\hline WIND & 0.1059 & 0.0153 & 48.01 & 0.1077 & 0.0152 & 50.16 \\
\hline $\mathrm{WIND}^{2}$ & -0.0062 & 0.0010 & 39.42 & -0.0064 & 0.0010 & 41.38 \\
\hline TEMP & 0.0235 & 0.0031 & 56.80 & 0.0226 & 0.0030 & 56.17 \\
\hline TEMP $^{2}$ & -0.00044 & 0.00004 & 116.89 & -0.00043 & 0.00004 & 119.15 \\
\hline CHLORO & -2.5055 & 0.3293 & 57.90 & -2.1819 & 0.1569 & 193.40 \\
\hline CHLORO $^{2}$ & 1.4116 & 1.2600 & 1.25 & & & \\
\hline AIC & & & 53.7 & & & 57.3 \\
\hline$\Delta$ & & & 0.0 & & & 3.6 \\
\hline$W$ & & & 0.858 & & & 0.142 \\
\hline Cumulative $W$ & & & 0.858 & & & 1.000 \\
\hline Adj. $r^{2}$ & & & 0.667 & & & 0.667 \\
\hline
\end{tabular}

Environmental predictors are: CHLORO, chlorophyll concentration $\left(\mathrm{mg} \mathrm{m}^{-3}\right.$, double- $\log _{10}$-transformed); TEMP, mean annual air temperature $\left({ }^{\circ} \mathrm{C}\right)$; WIND, mean annual wind speed $\left(\mathrm{m} \mathrm{s}^{-1}\right)$; OCEAN-DIST, mean of longitudinal and latitudinal ocean distance. Codes for statistics used in model selection are: $\Delta$, model Akaike information criterion (AIC) minus that of the best-fit model; $W$, model Akaike weight (see Westphal et al., 2003); Cumulative $W$, cumulative Akaike weight of models ranked in descending order of Akaike weight; Adj. $r^{2}$, model adjusted $r^{2}$. For all $F$-values $P<0.0001$.

Table 3 Best-fit spatial generalized least squares models for procellariiform species richness that meet the criterion of $W \geq 0.1$, and which have a greater than $95 \%$ probability of including the best-fit model, based on cumulative Akaike weight (Cumulative $W$ ).

\begin{tabular}{|c|c|c|c|c|c|c|c|c|c|}
\hline \multirow[b]{2}{*}{ Predictor } & \multicolumn{3}{|l|}{ Model 1} & \multicolumn{3}{|l|}{ Model 2} & \multicolumn{3}{|l|}{ Model 3} \\
\hline & Slope & SE & $F_{1,2453}$ & Slope & SE & $F_{1,2454}$ & Slope & SE & $F_{1,2454}$ \\
\hline OCEAN-DIST & 0.000011 & 0.000001 & $59.17^{\star * * *}$ & 0.000012 & 0.000001 & $60.80^{\star * \star *}$ & 0.000011 & 0.000001 & $58.74^{* * * *}$ \\
\hline WIND & 0.0325 & 0.0037 & $75.95^{\star * * *}$ & 0.0328 & 0.0037 & $77.66^{\star * * *}$ & 0.0324 & 0.0037 & $75.42^{* * * *}$ \\
\hline TEMP & 0.0327 & 0.0036 & $81.36^{* * * *}$ & 0.0325 & 0.0036 & $80.30^{* * * *}$ & 0.0331 & 0.0036 & $83.96^{\star * * *}$ \\
\hline TEMP $^{2}$ & -0.00045 & 0.00005 & $80.45^{\star * * *}$ & -0.00045 & 0.00005 & $79.02^{* * * *}$ & -0.00046 & 0.00005 & $83.35^{* * * *}$ \\
\hline CHLORO & -0.2793 & 0.2188 & 1.63 & & & & -0.4550 & 0.0937 & $23.59^{* * * *}$ \\
\hline CHLORO $^{2}$ & -0.6646 & 0.7480 & 0.79 & -1.5277 & 0.3201 & $22.79^{* * * *}$ & & & \\
\hline AIC & & & -4603.3 & & & -4602.9 & & & -4601.3 \\
\hline$\Delta$ & & & 0.0 & & & 0.4 & & & 2.0 \\
\hline$W$ & & & 0.454 & & & 0.372 & & & 0.167 \\
\hline Cumul $W$ & & & 0.454 & & & 0.826 & & & 0.993 \\
\hline
\end{tabular}

Environmental predictors are: CHLORO, chlorophyll concentration $\left(\mathrm{mg} \mathrm{m}^{-3}\right.$, double- $\log _{10}$-transformed); TEMP, mean annual air temperature $\left({ }^{\circ} \mathrm{C}\right)$; WIND, mean annual wind speed $\left(\mathrm{m} \mathrm{s}^{-1}\right)$; OCEAN-DIST, mean of longitudinal and latitudinal ocean distance. Codes for statistics used in model selection are: $\Delta$, model Akaike information criterion (AIC) minus that of the best-fit model; $W$, model Akaike weight (see Westphal et al., 2003). ${ }^{* * * *} P<0.0001$.

linear term for WIND and finally CHLORO, with the quadratic relationship for the latter again only marginally improving fit. Nevertheless, the latitudinal asymmetry in species richness means that global single-predictor relationships are not simple (Fig. 4).

Model selection procedures involving spatial GLS and nonspatial OLS modelling of all combinations of our three energy predictors, hence omitting OCEAN-DIST, confirmed the explanatory importance of the latter predictor (Tables S1 \& S2, reporting higher AIC values). The estimated variance explained by the best OLS model was $47.9 \%$ (Table S2). Hence, the fit of
OCEAN-DIST contributed an estimated $18.8 \%$ explained variation to the OLS models. Otherwise the conclusions concerning the relative fit of energy predictors were broadly the same as for the model selection results that included OCEAN-DIST. Model selection involving the fit only of energy predictors confirmed that all three energy measures were required predictors in bestfit models (associated Akaike weights summing to 1.0 in all cases). Moreover, in both GLS and OLS procedures they confirmed that the fit of WIND was positive linear when accounting for the fit of other energy forms. They further confirmed that the fit of TEMP was strongly hump-shaped quadratic, and 
Table 4 Hierarchical partitioning results for each of the four predictors of procellariiform species richness. Average independent and joint effects are computed using adjusted $r^{2}$ and log-likelihoods in the case of non-spatial ordinary least squares (OLS) and spatial generalized least squares (GLS) models, respectively.

\begin{tabular}{|c|c|c|c|c|c|c|}
\hline \multirow[b]{3}{*}{ Predictor } & \multicolumn{3}{|l|}{ OLS } & \multicolumn{3}{|l|}{ GLS } \\
\hline & \multicolumn{3}{|c|}{ Contribution (adjusted $r^{2}$ ) } & \multicolumn{3}{|c|}{ Contribution (log-likelihood) } \\
\hline & Independent $(I)$ & Joint $(J)$ & $I: J$ ratio & Independent $(I)$ & Joint $(J)$ & $I: J$ ratio \\
\hline WIND & 0.12 & 0.18 & 0.64 & 46.88 & 31.17 & 1.50 \\
\hline TEMP & 0.11 & 0.10 & 1.12 & 52.66 & 35.49 & 1.48 \\
\hline CHLORO & 0.06 & 0.09 & 0.67 & 27.58 & 34.00 & 0.81 \\
\hline OCEAN-DIST & 0.31 & 0.23 & 1.36 & 51.76 & 54.47 & 0.95 \\
\hline
\end{tabular}

Environmental predictors are: CHLORO, chlorophyll concentration $\left(\mathrm{mg} \mathrm{m}^{-3}\right.$, double- $\log _{10}$-transformed); TEMP, mean annual air temperature $\left({ }^{\circ} \mathrm{C}\right)$; WIND, mean annual wind speed $\left(\mathrm{m} \mathrm{s}^{-1}\right)$; OCEAN-DIST, mean of longitudinal and latitudinal ocean distance.

Table 5 Single-predictor non-spatial ordinary least squares (OLS) models of two ocean distance and three energy predictors of procellariiform species richness. Results contrast models fitting a single term for each predictor [linear or quadratic term, whichever has the lowest Akaike information criterion (AIC) and hence best fit] and those fitting two terms (linear and quadratic). The AIC value for the overall best-fitting model for each of the four predictors is highlighted in bold. Otherwise all abbreviations and statistical codes are as for Tables 1 \& 2 .

\begin{tabular}{|c|c|c|c|c|c|c|c|c|c|}
\hline Predictor & Slope (SE) & $F_{1,2460}$ & AIC & $\operatorname{Adj}-r^{2}$ & Predictor & Slope (SE) & $F_{1,2459}$ & AIC & Adj- $r^{2}$ \\
\hline OCEAN-DIST & $\begin{array}{c}0.000056 \\
(0.000001)\end{array}$ & $1966.60^{* * * *}$ & 731.6 & 0.553 & $\begin{array}{l}\text { OCEAN- DIST } \\
\text { OCEAN-DIST }^{2}\end{array}$ & $\begin{array}{c}0.000047 \\
(0.000004) \\
4 \mathrm{E}-10(0)\end{array}$ & $122.33^{\star * * *}$ & 769.8 & 0.554 \\
\hline $\mathrm{WIND}^{2}$ & $\begin{array}{c}0.0061 \\
(0.0002)\end{array}$ & $650.06^{* * * *}$ & 1589.9 & 0.364 & $\begin{array}{l}\text { WIND } \\
\text { WIND }^{2}\end{array}$ & $\begin{array}{c}-0.0188 \\
(0.0201) \\
0.0073 \\
(0.0013)\end{array}$ & $\begin{array}{l}0.87^{\star * * *} \\
31.20^{\star * * *}\end{array}$ & 1595.0 & 0.364 \\
\hline TEMP & $\begin{array}{c}-0.00012 \\
(0.00001)\end{array}$ & $228.54^{* * * *}$ & 1955.2 & 0.238 & $\begin{array}{l}\text { TEMP } \\
\text { TEMP }^{2}\end{array}$ & $\begin{array}{c}0.0708 \\
(0.0036) \\
-0.00097 \\
(0.00004)\end{array}$ & $\begin{array}{l}393.21^{\star * * *} \\
492.92^{\star * * *}\end{array}$ & 1599.7 & 0.365 \\
\hline $\mathrm{CHLORO}^{2}$ & $\begin{array}{l}-6.903 \\
(0.750)\end{array}$ & $84.82^{\star * * *}$ & 2067.4 & 0.222 & $\begin{array}{l}\text { CHLORO } \\
\text { CHLORO }^{2}\end{array}$ & $\begin{array}{c}1.264 \\
(0.420) \\
-11.78 \\
(1.79)\end{array}$ & $\begin{array}{c}9.06^{\star *} \\
43.53^{\star * * *}\end{array}$ & 2058.2 & 0.225 \\
\hline
\end{tabular}

$* * * * P<0.0001 ; * * 0.001 \leq P<0.01$.

Environmental predictors are: CHLORO, chlorophyll concentration ( $\mathrm{mg} \mathrm{m}^{-3}$, double- $\log _{10}$-transformed); TEMP, mean annual air temperature $\left({ }^{\circ} \mathrm{C}\right)$; WIND, mean annual wind speed $\left(\mathrm{m} \mathrm{s}^{-1}\right)$; OCEAN-DIST, mean of longitudinal and latitudinal ocean distance.

slightly decelerating negative quadratic relationship for CHLORO.

\section{DISCUSSION}

Of all combinations of predictors tested, both the best-fitting OLS and GLS models indicate that ocean distance and all three forms of energy are required to explain spatial variation in the species richness of procellariiform seabirds. Ocean distance is consistently important, irrespective of the regression method used, being the most important predictor in OLS models and a close second to temperature in GLS models. Wind and temperature switch in rank importance depending on the regression method used, but are consistently more important than ocean chlorophyll.

None of the energy forms tested appear adequately to account for the very marked latitudinal asymmetry in procellariiform species richness, although wind speeds are greater at high southern than high northern latitudes. On the other hand, ocean distance explains more of the latitudinal asymmetry, which is also why it shows a more linear global relationship with species richness (Fig. 4a). While productivity per unit area of ocean appears to be weakly associated with species richness at the sampling resolution analysed in this study, contiguous ocean extent may represent potential resource availability across very large geographical scales. Such scales are nevertheless meaning- 
Table 6 Single-predictor spatial generalized least squares (GLS) models of two ocean distance and three energy predictors of procellariiform species richness. The Akaike information criterion (AIC) value for the best-fitting model (lowest AIC) for each of the five predictors is highlighted in bold. Otherwise all abbreviations and statistical codes are as for Tables $1 \& 2$.

\begin{tabular}{|c|c|c|c|c|c|c|c|}
\hline Predictor & Slope (SE) & $F_{1,2458}$ & AIC & Predictor & Slope (SE) & $F_{1,2457}$ & AIC \\
\hline \multirow[t]{2}{*}{ OCEAN-DIST } & $\begin{array}{c}0.000019 \\
(0.000001)\end{array}$ & $194.83^{* * * *}$ & -4457.9 & OCEAN-DIST & $\begin{array}{c}0.000026 \\
(0.000003)\end{array}$ & $71.44^{* * * *}$ & -4421.2 \\
\hline & & & & OCEAN-DIST $^{2}$ & $-364 \mathrm{E}-12(0)$ & $6.86^{\star *}$ & \\
\hline \multirow[t]{2}{*}{ WIND } & $\begin{array}{c}0.0374 \\
(0.0039)\end{array}$ & $91.72^{\star * * *}$ & -4376.8 & WIND & $\begin{array}{c}0.0292 \\
(0.0148)\end{array}$ & $3.88^{\star}$ & -4365.1 \\
\hline & & & & $\mathrm{WIND}^{2}$ & $\begin{array}{c}0.00057 \\
(0.00099)\end{array}$ & 0.33 & \\
\hline \multirow[t]{2}{*}{ TEMP } & $\begin{array}{c}0.0053 \\
(0.0010)\end{array}$ & $31.36^{\star * * *}$ & -4313.2 & TEMP & $\begin{array}{c}0.0484 \\
(0.0034)\end{array}$ & $205.66^{\star * * *}$ & -4460.4 \\
\hline & & & & TEMP $^{2}$ & $\begin{array}{c}-0.00065 \\
(0.00005)\end{array}$ & $181.32^{* * * *}$ & \\
\hline \multirow[t]{2}{*}{ CHLORO $^{2}$} & $\begin{array}{c}-2.430 \\
(0.329)\end{array}$ & $54.46^{\star * \star *}$ & -4349.0 & CHLORO & $\begin{array}{c}-0.4526 \\
(0.2296)\end{array}$ & $3.89^{\star}$ & -4351.8 \\
\hline & & & & CHLORO $^{2}$ & $\begin{array}{c}-1.0163 \\
(0.7884)\end{array}$ & 1.66 & \\
\hline
\end{tabular}

$\left.{ }^{* * * *} P<0.0001 ;{ }^{* *} 0.001 \leq P<0.01 ;{ }^{*} 0.01 \leq P<0.05\right)$.

Environmental predictors are: CHLORO, chlorophyll concentration $\left(\mathrm{mg} \mathrm{m}^{-3}\right.$, double- $\log _{10}$-transformed); TEMP, mean annual air temperature $\left({ }^{\circ} \mathrm{C}\right)$; WIND, mean annual wind speed $\left(\mathrm{m} \mathrm{s}^{-1}\right)$; OCEAN-DIST, mean of longitudinal and latitudinal ocean distance.

ful in the context of procellariiform seabirds, given their ability to harness wind energy for long-distance foraging.

Earlier findings of Chown \& Gaston (1999) indicate a humpshaped response of procellariiform species richness to chlorophyll concentration. However, where the quadratic term for chlorophyll concentration enters best-fit models in the present study, the relationship is still essentially negative and is not a substantially better fit than the equivalent linear model. There are two alternative but not mutually exclusive explanations for this negative relationship. Expanding on the idea introduced above, the acquisition of sufficient oceanic productive energy for successful breeding and maintenance of population numbers may depend, crucially, on the opportunity to harness or benefit from other forms of available energy, for example wind or ambient energy (temperature). Second, since the relationship between mean levels of chlorophyll concentration and its variance is known to be positive (Chown \& Gaston, 1999), temporal variability in the availability of productive energy at higher energy levels may be limiting large-scale procellariiform species richness distribution, since individual species may be absent from areas where resources are highly variable.

Most procellariiform species breed on remote oceanic islets or islands, where they benefit from reduced predation pressure (Lack, 1968). However, this may be at the cost of intra- and interspecific density-dependent competition for proximate marine resources (Ashmole, 1971; Weimerskirch, 1998). Avoidance of competition increases the pay off to procellariiform species of using wind to facilitate long-distance foraging trips. Hence, procellariiform species should be able to maintain higher population numbers on remote islands than other species. In this way, the use of wind by these seabirds may represent an unusual example of support for the 'more individuals' hypothesis that underpins the variant of species-energy theory concerned with productive energy (Wright, 1983).

A more historical ocean area hypothesis offered by Chown et al. (1998a) proposes that greater levels of procellariiform species richness in the Pacific, compared with Atlantic and Indian oceans, are a consequence of the combination of greater ocean area and the abundance of islands, resulting in greater levels of allopatric speciation. It has previously been acknowledged that prehistoric extinctions have also influenced observed differences among ocean basins in contemporary procellariiform species richness distribution (Chown et al., 1998a). Evidence of North Atlantic Miocene to Pleistocene extinctions (Warham, 1996; Brooke, 2004) suggests that these may have contributed to the latitudinal asymmetry observed. Additionally, prehistoric anthropogenic extinctions on Pacific islands (Steadman, 1995; Wragg, 1995; Kirch, 1996) are evidence of extinction also operating at lower latitudes. However, since these are thought predominantly to have been local extinctions of island breeding populations (Steadman, 1995) with few entire species extinctions (Milberg \& Tyrberg, 1993; Gaston, 2004), any absolute latitudinal bias in influences on species foraging ranges remains uncertain. However, it might be argued that recent, anthropogenic extinctions of procellariiforms show a gradient from the tropics to the Southern Ocean, given late colonization of the latter by humans (Chown et al., 1998b, 2005), thus enhancing the likely relationship between richness and wind energy. No evidence for such a gradient has been documented, there is substantial variation in seabird local extirpation and extinction among islands (e.g. Steadman \& Kirch, 1990; Steadman, 1995; Steadman et al., 1999) and the disappearance of 
(a)

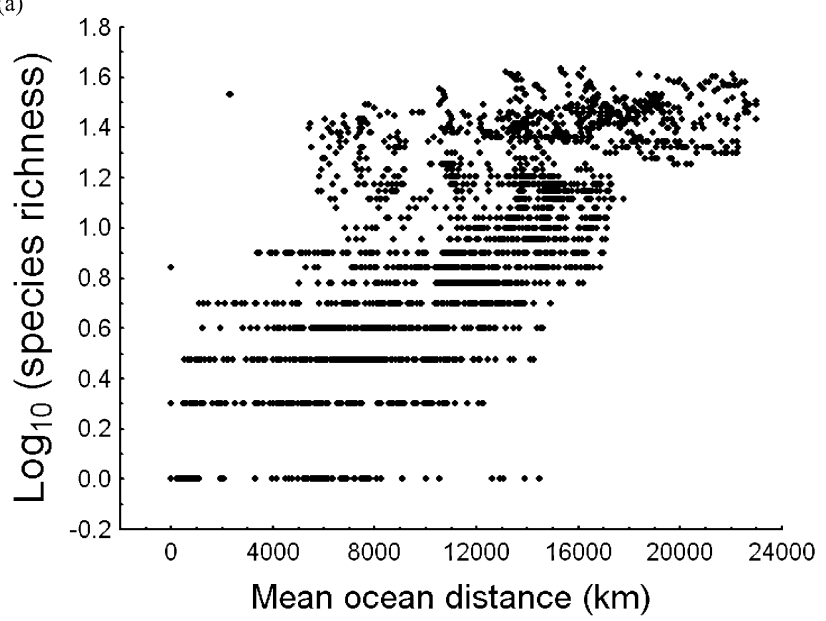

(b)

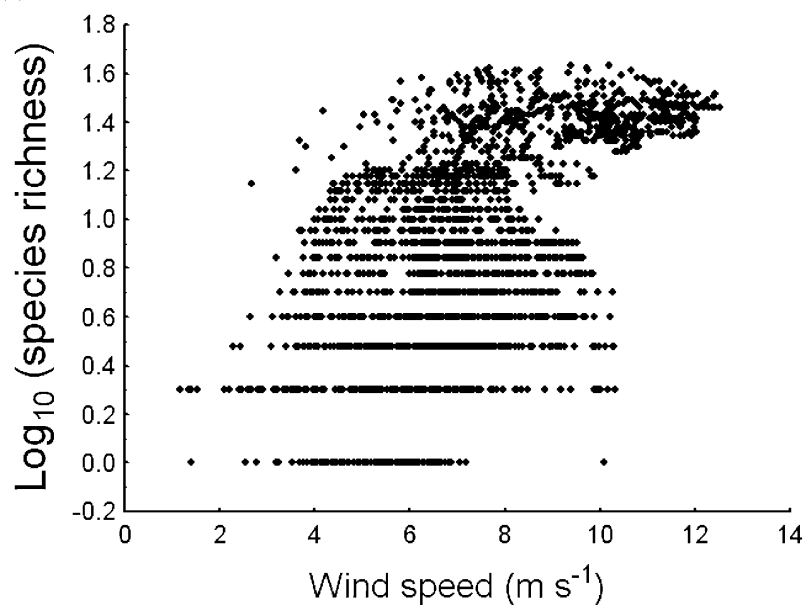

(c)

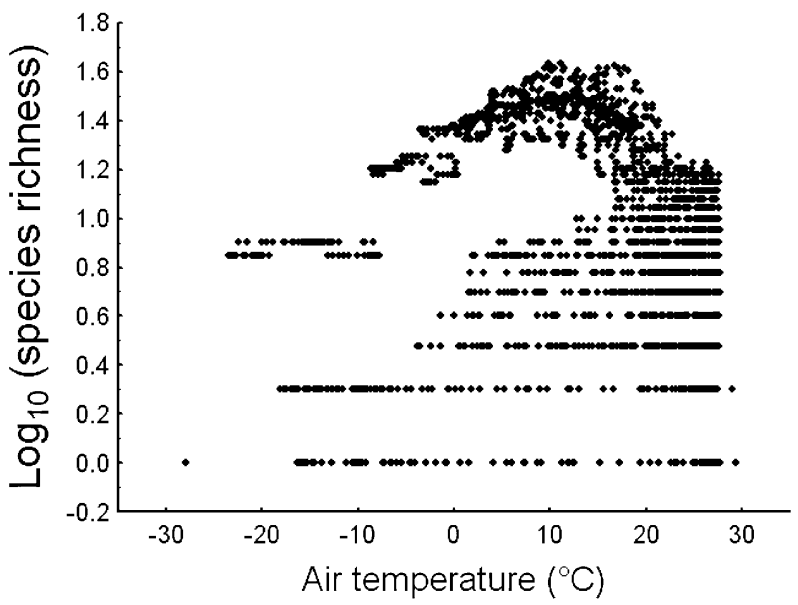

(d)

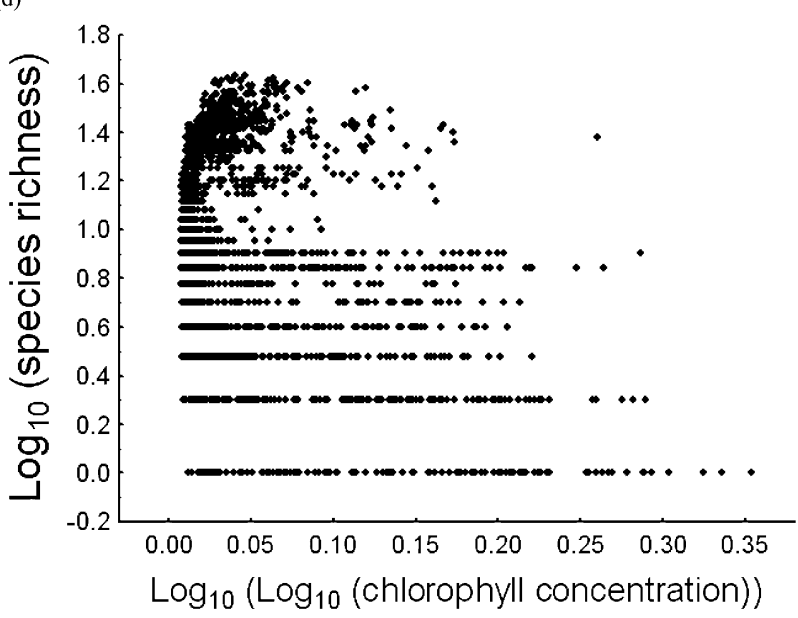

Figure 4 Plots of $\log _{10}$ (procellariiform species richness) against (a) mean ocean distance (km), (b) wind speed ( $\left.\mathrm{m} \mathrm{s}^{-1}\right)$, (c) air temperature $\left({ }^{\circ} \mathrm{C}\right)$ and $(\mathrm{d}) \log _{10}\left[\log _{10}\right.$ (chlorophyll concentration) $]$.

procellariiform species from islands has not been limited to tropical areas (Warham, 1996; Gaston, 2004). Moreover, recent reviews have not emphasized the significance of anthropogenic extinctions for determining present variation in procellariiform richness, focusing rather on the paucity of species in the high northern latitudes (Brooke, 2004; Gaston, 2004). The latter paucity partly represents a lack of narrow-ranging endemic species, compared with equivalent southern latitudes, suggesting the hemispherical asymmetry is unlikely to be explained by a null model of random species range distributions in relation to ocean area (Chown et al., 1998a). Overall, it seems unlikely that local and/or global extinctions have influenced spatial variation in richness in such a way that its relationship with energy, and specifically wind speed, is an artefact. Nonetheless, the influence of anthropogenic extinctions on procellariiform species richness deserves further scrutiny, given the apparent sensitivity, especially of the Procellariidae, to threat (Bennett \& Owens, 1997). Clearly, the varying roles of energy availability and ocean extent, speciation and extinction events, are likely to have interacted in their contributions to the species richness patterns currently observed.
Concerns over the consequences of global climate change for the survival of procellariiform species have included the issues of sea level rise and other ecological changes affecting island breeding populations, and of changes in sea temperature causing shifts in the proximity of marine resources (Brooke, 2004). This study suggests that potential changes to large-scale wind currents may be a further global climate change issue of relevance to the future distribution of pelagic seabirds.

The ecological influence of wind speed gradients on biodiversity distribution obviously has significance beyond the main focus of the present study. A topic not covered here, but which may yet be of relevance, is the link between wind energy and patterns of ocean upwelling associated with high biological productivity (Rykaczewski \& Checkley, 2008) and its likely consequences for marine biodiversity. Wind energy may also influence the distributional ranges of some terrestrial taxa, and hence large-scale patterns of terrestrial diversity. Overall, however, the influence of wind is likely to be subordinate to that of productive energy, and negative for the large majority of taxa considered given the interaction between wind and temperature via wind chill. Positive species-wind energy relationships may be confined 
to a relatively small number of groups that are pre-adapted or highly evolved to take advantage of wind. However, likely candidate groups are those that contradict the classical latitudinal diversity gradient in which species richness peaks at the equator.

While this study has been largely concerned with present-day ecological responses to energy gradients, latitudinal wind speed gradients may also play a role in evolutionary mechanisms that determine the large-scale distribution of biological diversity. For example, dispersal potential, range size and consequent predisposition to allopatric speciation, are all species traits that may be modulated by large-scale wind-speed gradients (e.g. Winkworth et al., 2002; Muñoz et al., 2004; Renner, 2004). Important insights contributing to on-going development of speciesenergy theory may therefore be made through further investigations into the role of wind as well as other forms of available environmental energy.

\section{ACKNOWLEDGEMENTS}

We are grateful to Ian Harris of the Climatic Research Unit at the University of East Anglia for providing temporally averaged global wind and temperature data, and to Peter Harrison for correspondence about seabird distributions. We thank David Currie, Alexandre Diniz-Filho, Karl Evans, Marco Pautasso and three anonymous referees for comments and discussion on the manuscript. This work was supported by NERC grant NER/O/ S/2001/0125 and by the DST-NRF Centre of Excellence for Invasion Biology.

\section{REFERENCES}

Abrams, R.W. (1985) Environmental determinants of pelagic seabird distribution in the African sector of the southern ocean. Journal of Biogeography, 12, 473-492.

Adams, N.J., Brown, C.R. \& Nagy, K.A. (1986) Energy expenditure of free-ranging wandering albatrosses Diomedea exulans. Physiological Ecology, 59, 583-591.

Ainley, D.G., Ribic, C.A. \& Fraser, W.R. (1994) Ecological structure among migrant and resident seabirds of the ScotiaWeddell Confluence region. Journal of Animal Ecology, 63, 347-364.

Ashmole, N.P. (1971) Seabird ecology and the marine environment. Avian biology, Vol. 1 (ed. by D.S. Farner and J.R. King), pp. 223-286. Academic Press, London.

Bennett, P.M. \& Owens, I.P.F. (1997) Variation in extinction risk among birds: chance or evolutionary predisposition? Proceedings of the Royal Society B: Biological Sciences, 264, 401-408.

Birt-Friesen, V.L., Montevecchi, W.A., Cairns, D.K. \& Macko, S.A. (1989) Activity-specific metabolic rates of free-living northern gannets and other seabirds. Ecology, 70, 357-367.

Blackburn, T.M., Gaston, K.J. \& Lawton, J.H. (1998) Patterns in the geographic ranges of the world's woodpeckers. Ibis, 140, 626-638.

Brooke, M. (2004) Albatrosses and petrels across the world. Oxford University Press, Oxford.
Burnham, K.P. \& Anderson, D.R. (2002) Model selection and multi-model inference: a practical information-theoretic approach, 2nd edn. Springer-Verlag, New York.

Chaurand, T. \& Weimerskirch, H. (1994) The regular alternation of short and long trips in the blue petrel Halobaena caerulea: a previously undescribed strategy of food-provisioning in a pelagic seabird. Journal of Animal Ecology, 63, 275-282.

Chevan, A. \& Sutherland, M. (1991) Hierarchical partitioning. The American Statistician, 45, 90-96.

Chown, S.L. \& Gaston, K.J. (1999) Patterns in procellariiform diversity as a test of species-energy theory in marine systems. Evolutionary Ecology Research, 1, 365-373.

Chown, S.L., Gaston, K.J. \& Williams, P.H. (1998a) Global patterns in species richness of pelagic seabirds: the Procellariiformes. Ecography, 21, 342-350.

Chown, S.L., Gremmen, N.J.M. \& Gaston, K.J. (1998b) Ecological biogeography of southern ocean islands: species-area relationships, human impacts, and conservation. The American Naturalist, 152, 562-575.

Chown, S.L., Hull, B. \& Gaston, K.J. (2005) Human impacts, energy availability, and invasion across Southern Ocean Islands. Global Ecology and Biogeography, 14, 521-528.

Clifford, P., Richardson, S. \& Hemon, D. (1989) Assessing the significance of the correlation between two spatial processes. Biometrics, 45, 123-134.

Cressie, N. (1991) Statistics for spatial data. Wiley, New York. Croxall, J.P., Silk, J.R.D., Phillips, R.A., Afanasyev, V. \& Briggs, D.R. (2005) Global circumnavigations: tracking year-round ranges of nonbreeding albatrosses. Science, 307, 249-250.

Currie, D.J. (1991) Energy and large-scale patterns of animaland plant-species richness. The American Naturalist, 137, 27-49.

Diniz-Filho, J.A.F., Rangel, T.F.L.V.B.. \& Bini, L.M. (2008) Model selection and information theory in geographical ecology. Global Ecology and Biogeography, 17, 479-488.

Ellis, H.I. (1984) Energetics of free-ranging seabirds. Seabird energetics (ed by G.C. Whittow and H. Rahn), pp. 203-234. Plenum Press, New York.

ESRI (1993) Digital chart of the world. Environmental Systems Research Institute Inc., Redlands, CA.

Evans, K.L., Warren, P.H. \& Gaston, K.J. (2005) Species-energy relationships at the macroecological scale: a review of the mechanisms. Biological Reviews of the Cambridge Philosophical Society, 80, 1-25.

Furness, R.W. \& Bryant, D.M. (1997) Effect of wind on field metabolic rates of breeding northern fulmars. Ecology, 77, 1181-1188.

Gaston, A.J. (2004) Seabirds: a natural history. T \& A D Poyser, London.

Harrison, P. (1989) Seabirds: an identification guide. Croom Helm, London.

Hashmi, D. \& Causey, D. (2008) A system in which available energy per se controls alpha diversity: marine pelagic birds. The American Naturalist, 171, 419-429.

Hovis, W.A., Clark, D.K., Anderson, F., Austin, R.W., Wilson, W.H., Baker, E.T., Ball, D., Gordon, H.R., Mueller, J.L., 
El-Sayed, S.Z., Sturm, B., Wrigley, R.C. \& Yentsch, C.S. (1980) Nimbus-7 Coastal Zone Color Scanner: system description and initial imagery. Science, 210, 60-63.

Hunt, G.L., Priddle, J., Whitehouse, M.J., Veit, R.R. \& Heywood, R.B. (1992) Changes in seabird species abundance near South Georgia during a period of rapid change in sea surface temperature. Antarctic Science, 4, 15-22.

Inchausti, P., Guinet, C., Koudil, M., Durbec, J.-P., Barbraud, C., Weimerskirch, H.I., Cherel, Y. \& Jouventin, P. (2003) Interannual variability in the breeding performance of seabirds in relation to oceanographic anomalies that affect the Crozet and the Kerguelen sectors of the Southern Ocean. Journal of Avian Biology, 34, 170-176.

Johnson, J.B. \& Omland, K.S. (2004) Model selection in ecology and evolution. Trends in Ecology and Evolution, 19, 101-108.

Jouventin, P. \& Weimerskirch, H. (1990) Satellite tracking of wandering albatrosses. Nature, 343, 746-748.

Kirch, P.V. (1996) Late Holocene human-induced modifications to a central Polynesian island ecosystem. Proceedings of the National Academy of Sciences USA, 93, 5296-5300.

Lack, D. (1968) Ecological adaptations for breeding in birds. Methuen, London.

Littell, R.C., Milliken, G.A., Strop, W.W. \& Wolfinger, R.D. (1996) SAS system for mixed models. SAS Institute, Cary, NC.

MacNally, R. (2000) Regression and model-building in conservation biology, biogeography and ecology: the distinction between - and reconciliation of - 'predictive' and 'explanatory' models. Biodiversity and Conservation, 9, 655-671.

Milberg, P. \& Tyrberg, T. (1993) Naïve birds and noble savages a review of man-caused prehistoric extinctions of island birds. Ecography, 16, 229-250.

Muñoz, J., Felicísimo, Á.M., Cabezas, F., Burgaz, A.R. \& Martínez, I. (2004) Wind as a long-distance dispersal vehicle in the southern hemisphere. Science, 304, 1144-1147.

Nagy, K.A., Girard, I.A. \& Brown, T.K. (1999) Energetics of free-ranging mammals, reptiles and birds. Annual Reviews of Nutrition, 19, 247-277.

Pennycuick, C.J. (1982) The flight of petrels and albatrosses (Procellariiformes), observed in South Georgia and its vicinity. Philosophical Transactions of the Royal Society of London Series B, Biological Sciences, 300, 75-106.

Pennycuick, C.J. (1989) Bird flight performance: a practical calculation manual. Oxford University Press, Oxford.

Pennycuick, C.J. (2002) Gust soaring as a basis for the flight of petrels and albatrosses (Procellariiformes). Avian Science, 2, $1-12$.

Platt, T. \& Sathyendranath, S. (1988) Oceanic primary production: estimation by remote sensing at local and regional scales. Science, 241, 1613-1620.

Quinn, G.P. \& Keough, M.J. (2002) Experimental design and data analysis for biologists. Cambridge University Press, Cambridge.

Rangel, T.F.L.V.B., Diniz-Filho, J.A.F. \& Bini, L.M. (2005) SAM v.1.1 - spatial analysis in macroecology (software and user's guide). Available at: http://www.ecoevol.ufg.br/sam/ (accessed 28 September 2007).
Rangel, T.F.L.V.B., Diniz-Filho, J.A.F. \& Bini, L.M. (2006) Towards an integrated computational tool for spatial analysis in macroecology and biogeography. Global Ecology and Biogeography, 15, 321-327.

Renner, S. (2004) Plant dispersal across the tropical Atlantic by wind and sea currents. International Journal of Plant Science, 165 (Suppl.), S23-S33.

Rohde, K. (1992) Latitudinal gradients in species diversity, the search for the primary cause. Oikos, 65, 514-527.

Rykaczewski, R.R. \& Checkley, D.M. (2008) Influence of ocean winds on the pelagic ecosystem in upwelling regions. Proceedings of the National Academy of Sciences USA, 105, 19651970.

Shaffer, S.A., Costa, D.P. \& Weimerskirch, H. (2001) Behavioural factors affecting foraging effort of breeding wandering albatrosses. Journal of Animal Ecology, 70, 864-874.

Steadman, D.W. (1995) Prehistoric extinctions of Pacific island birds: biodiversity meets zooarchaeology. Science, 267, 11231131.

Steadman, D.W. \& Kirch, P.V. (1990) Prehistoric extinction of birds on Mangaia, Cook Islands, Polynesia. Proceedings of the National Academy of Sciences USA, 87, 9605-9609.

Steadman, D.W., White, J.P. \& Allen, J. (1999) Prehistoric birds from New Ireland, Papua New Guinea: extinctions on a large Melanesian island. Proceedings of the National Academy of Sciences USA, 96, 2563-2568.

Turner, J.R.G., Gatehouse, C.M. \& Corey, C.A. (1987) Does solar energy control organic diversity? Butterflies moths and the British climate. Oikos, 48, 195-205.

Turner, J.R.G., Lennon, J.J. \& Lawrenson, J.A. (1988) British bird species distributions and the energy theory. Nature, 335, 539541.

Warham, J. (1996) The behaviour, population biology and physiology of the petrels. Academic Press, London.

Weimerskirch, H. (1998) How can a pelagic seabird provision its chick when relying on a distant food resource? Cyclic attendance at the colony, foraging decision and body condition in sooty shearwaters. Journal of Animal Ecology, 67, 99-109.

Weimerskirch, H., Salamolard, M., Sarrazin, F. \& Jouventin, P. (1993) Foraging strategy of wandering albatrosses through the breeding season: a study using satellite telemetry. Auk, 110, 325-342.

Weimerskirch, H., Cherel, Y., Cuenot-Chaillet, F. \& Ridoux, V. (1997) Alternative foraging strategies and resource allocation by male and female wandering albatrosses. Ecology, 78, 20512063.

Weimerskirch, H., Guionnet, T., Martin, J., Shaffer, S.A. \& Costa, D.P. (2000) Fast and fuel-efficient? Optimal use of wind by flying albatrosses. Proceedings of the Royal Society B: Biological Sciences, 267, 1869-1874.

Westphal, M.I., Field, S.A., Tyre, A.J., Paton, D. \& Possingham, H.P. (2003) Effects of landscape pattern on bird species distribution in the Mt. Lofty Ranges, South Australia. Landscape Ecology, 18, 413-426.

Williams, P.H. (1999) WORLDMAP 4.2 WINDOWS: software and user document 4.1. Privately distributed, London. 
Willig, M.R., Kaufman, D.M. \& Stevens, R.D. (2003) Latitudinal gradients of biodiversity: pattern, process, scale and synthesis. Annual Review of Ecology, Evolution and Systematics, 34, 273309.

Wilson, J.A. (1975) Sweeping flight and soaring by albatrosses. Nature, 257, 307-308.

Winkworth, R.C., Wagstaff, S.J., Glenny, D. \& Lockhart, P.J. (2002) Plant dispersal N.E.W.S from New Zealand. Trends in Ecology and Evolution, 17, 514-520.

Wragg, G.M. (1995) The fossil birds of Henderson Island, Pitcairn group - natural turnover and human impact, a synopsis. Biological Journal of the Linnean Society, 56, 405-414.

Wright, D.H. (1983) Species-energy theory: an extension of species-area theory. Oikos, 41, 496-506.

Wright, D.H., Currie, D.J. \& Maurer, B.A. (1993) Energy supply and patterns of species richness on local and regional scales. Species diversity in ecological communities: historical and geographical perspectives (ed. by R.E. Ricklefs and D. Schluter), pp. 66-77. University of Chicago Press, Chicago, IL and London.

\section{SUPPORTING INFORMATION}

Additional Supporting Information may be found in the online version of this article:

Figure S1 Semi-variogram comparing best-fit spatial GLS model residuals and equivalent non-spatial ordinary least squares model residuals.

Table S1 Best-fit spatial generalized least squares models for procellariiform species richness, excluding measures of ocean distance, that meet the criterion of $W \geq 0.1$, and which have a greater than $95 \%$ probability of including the best-fit model
Table S2 Best-fit non-spatial ordinary least squares models for procellariiform species richness, excluding measures of ocean distance, that meet the criterion of $W \geq 0.1$, and which have a greater than $95 \%$ probability of including the best-fit model

As a service to our authors and readers, this journal provides supporting information supplied by the authors. Such materials are peer-reviewed and may be reorganized for online delivery, but are not copy-edited or typeset. Technical support issues arising from supporting information (other than missing files) should be addressed to the authors.

\section{BIOSKETCHES}

Richard G. Davies is interested in ecological and evolutionary determinants of patterns of biodiversity at different spatial scales.

Ulrike M. Irlich is interested in large-scale patterns in biodiversity at all hierarchical levels.

Steven L. Chown works in the fields of macroecology, evolutionary physiology and invasion biology. He has a long-standing interest in the ecology, physiology and evolution of the biotas of the Southern Ocean islands.

Kevin J. Gaston has research interests in the fields of biodiversity, conservation biology and macroecology, with particular emphasis on the ecologies of rare organisms, the structure of geographical ranges and patterns in species richness.

Editor: José Alexandre F. Diniz-Filho 